\title{
Dissecting the rural Indian women's knowledge, attitude and practice about infertility
}

\author{
Ashwini Nayak U.*, Ramakrishnan K. G., Venkateswar K. N., Vijayshree M.
}

Department of Obstetrics and Gynecology, M. S. Ramaiah Medical College, Bengaluru, Karnataka, India

Received: 26 June 2017

Accepted: 10 July 2017

\section{*Correspondence:}

Dr. Ashwini Nayak U.,

E-mail: ashwininayaku@gmail.com

Copyright: () the author(s), publisher and licensee Medip Academy. This is an open-access article distributed under the terms of the Creative Commons Attribution Non-Commercial License, which permits unrestricted non-commercial use, distribution, and reproduction in any medium, provided the original work is properly cited.

\begin{abstract}
Background: Objective of present study was to evaluate the knowledge, attitude and practice of rural women regarding infertility.

Methods: A field tested semi-structured questionnaire was administered to 100 rural women in Kaiwara village, Karnataka, India to study their knowledge, attitude and practice regarding infertility.

Results: Majority $(84 \%)$ did not know the reason for infertility. $7 \%$ felt that the cause of infertility was due to problems with eggs, $6 \%$ felt it to be tubal factors and only $3 \%$ felt it to be due to male factor.

Conclusions: The findings of this study highlight the importance of spreading the awareness and inculcating the right attitude and approach to infertility.
\end{abstract}

Keywords: Attitude, Infertility, Knowledge, Practice

\section{INTRODUCTION}

Infertility is a worldwide problem affecting 8-12 percent couple (50-80 million) during their reproductive lives (WHO, 1991). ${ }^{1}$ The WHO estimates the overall prevalence of primary infertility in India to be between 3.9 and 16.8 per cent. ${ }^{2}$ Infertility has stigmatised women from time immemorial. Women who are deemed to be infertile are often excluded from religious practices and face many such social difficulties. In fact, the ease with which women can be labelled infertile or resist the label, the experiences of childless women and the process of seeking solutions for infertility all go beyond the biological fact of reproductive impairment. ${ }^{3}$ Further, male factor of infertility is a taboo subject and is less often discussed in the society. This constrains the relationship of the couples resulting in divorces. Even if the couple seek treatment, women are often blamed for childlessness and she alone is expected to undergo the diagnostic procedures to know the cause of infertility. Moreover, people in developing countries when faced with infertility resort to folk medicine, tantric practices and avail the help of quacks instead of seeking medical attention. The prohibitive cost, inadequate availability of health services pertaining to infertility have further aggravated the situation. Hence it becomes important to understand the perceptions of these couples regarding infertility and its management in order to be able to provide more effective solutions. The aim of our study was to assess the knowledge and attitudes of participants regarding infertility, its causes, health seeking behaviour and the source of the knowledge gathered.

\section{METHODS}

This cross- sectional study was conducted in the rural field practice area of Ramaiah medical college at Kaiwara village, in the Chintamani taluk of Chickaballapur district of Karnataka, India. Married women between the age of 18 and 65 years, capable of effectively communicating in their local language were included in the study, while women with mental impairment and other difficulties in 
communication were excluded. Only the permanent residents of the village were included. According to WHO, the national prevalence of primary and secondary infertility in India is $3 \%$ and $8 \%$ respectively. ${ }^{4,5}$ On the basis of the above-mentioned findings with a relative precision of \pm 1 and confidence level of $95 \%$, it was estimated 100 women need to be included for the study. A semi-structured, field-tested survey questionnaire was developed based on the existing literature to know about the knowledge and attitude of the participants towards infertility. Survey questionnaire comprised three components: first, sociodemographic details of the study population; second, knowledge about risk factors of infertility and health seeking behavior, third, and the sources of information. To assess socioeconomic status, Kuppuswamy classification was used. Random sampling of study subjects was followed among households. Interview was administered to participants after describing to them the aim of the study, obtaining oral consent, and confidentiality was maintained. A thorough rapport was established with the household members before collecting the information, and privacy was maintained with the informants while collecting the information. Statistical Analysis of the Data was carried out employing SPSS, version 18.0. Descriptive statistics was employed to summarize the quantitative variables. $\mathrm{P}$ $<0.05$ was considered significant.

\section{RESULTS}

The mean age of the female partner was 28.3years \pm 5.76 and ranged from 18 to 45 years, while that of the male partner was $32.2 ; \pm 6.64$. The average number of years of married life among the women in this study was found to be $21.82 \pm 3.93$ (18-32 years). $98 \%$ of the couples were Hindus. $55 \%$ of women revealed no formal education, while $35 \%$ were educated up to school education and $10 \%$ were graduates. $7 \%$ felt that the cause of infertility was due to problems with eggs, $6 \%$ felt it due to tubal factors, only $3 \%$ felt it be due to male factor (Table 1 ).

Table 1: Showing the distribution of the perception of rural women regarding the causes of infertility.

\begin{tabular}{|l|l|}
\hline Reasons of infertility & $\%$ \\
\hline Problems with eggs & 7 \\
\hline Tubal factor & 6 \\
\hline Male factor & 3 \\
\hline Did not know the reason & 84 \\
\hline
\end{tabular}

Majority (84\%) did not know the reason for infertility. Only $7 \%$ of the participants were infertile. Out of this, only $1 \%$ was ready to accompany the wife for investigation and treatment. $21 \%$ of the participants felt that local doctors could treat the infertility, $36 \%$ felt that government hospitals would be the best place for treatment, $23 \%$ felt that treatment should be taken at higher centres, $18 \%$ felt that they would rather go to religious places for fertility issues. Only $2 \%$ of the participants said they had gone to quacks for treatment.
$37 \%$ of the participants had the correct knowledge about ovulation. When the participants were asked about the timing of ovulation, $16 \%$ felt that it happens multiple times in the month, $13 \%$ felt it can happen anytime of the month, $1 \%$ felt it happens during the first week, $7 \%$ felt that it happens during the 2 nd week, $7 \%$ felt that it happens in the third week and $56 \%$ did not know about it. $3 \%$ felt that only 1 egg is released, $29 \%$ felt that 2 eggs are released, $29 \%$ felt that multiple eggs are released and the rest $39 \%$ had no knowledge about it. $37 \%$ had knowledge about sperms while $41 \%$ knew as to what was fertilization. $36 \%$ felt that the egg gets fertilized in the womb, $4 \%$ felt that it happens in the tube and $7 \%$ happens in the vagina. 52\% had the knowledge about implantation. $63 \%$ felt that one has to seek help before 1 year for infertility problem. $63 \%$ of the women were ready to seek help while only $14 \%$ of the husbands were ready to seek help. $21 \%$ had the knowledge that smoking and alcohol consumption can decrease the sperm count. $31 \%$ knew about the concept of timed intercourse. 9\% had knowledge about intrauterine insemination, $10 \%$ knew about IVF, $31 \%$ knew about surrogacy and $10 \%$ about the donation of sperms and eggs. $11 \%$ had learnt about childlessness from radio, $50 \%$ from television, $11 \%$ from newspaper, $2 \%$ got to know about it from elders, $3 \%$ from friends, $2 \%$ from posters and $3 \%$ from doctors.

\section{DISCUSSION}

Infertility has widespread ramifications not only social and cultural but financial also. Knowledge about this crucial issue is quintessential in proper treatment. In our study $55 \%$ of women who participated in the study revealed no formal education, while $35 \%$ were educated up to school education and $10 \%$ were graduates. A recent study by Bunting et al showed that sampling fertility patients from 79 countries found that accurate fertility knowledge was reported by only $56.9 \%$ of patients, supporting the need for more education which is also corroborated by our study. ${ }^{6}$ In the present study, the mean age of the female partner was 28.3years \pm-5.76 and ranged from 18 to 45 years, while that of the male partner was $32.2 ; \pm 6.64$ and this is in contrast to another study by Animasahun $\mathrm{VJ}$ et al where in the respondents were aged between 19 and 60 years, with a mean of 39.7 49.9 years which is a decade more than our study. ${ }^{7}$ When asked about ovulation, only $37 \%$ of the participants had the correct knowledge about ovulation. In contrast to this the study by Lisbet et al showed that the majority $(70 \%)$ of those trying to conceive were aware that clear mucous vaginal discharge is a sign of imminent ovulation; close to one-third timed coitus to signs of ovulation, and $20 \%$ had sex on a schedule. ${ }^{8}$ The difference in the awareness may be because of the fact that the later study was conducted on infertility patients exclusively. In the present study, respondents tried to gather information from various sources- $11 \%$ had learnt about childlessness from radio, $50 \%$ from television, $11 \%$ from newspaper, $2 \%$ got to know about it from elders, $3 \%$ from friends, $2 \%$ from posters and $3 \%$ from doctors, totally amounting 
to $82 \%$. This shows that media has a large role in disseminating information and creating awareness about infertility. When asked about the place they would go to for getting treated, $18 \%$ felt that they would rather go to religious places for fertility issues and only $2 \%$ of the participants said they had gone to quacks for treatment in the current study. This is in contrast to the study done in Nigeria by Lamaran Dattijo et al in which more than $35.2 \%$ of the respondents said evil spirits and $37.7 \%$ said witchcraft contributed to infertility. ${ }^{9}$ This study has thrown light on the value of research in this area as lack of education in the matters of fertility may be the crux of the problem for people not availing the medical facilities in this regard. Creating awareness among people about fertility issues may go a long way in reducing its prevalence. The greatest strength of the study is that this is the easiest way to know the baseline knowledge of respondents and also it gives an opportunity to educate the participants in the areas which they are unaware of. The limitation of this study is that it may not be truly representative of all the Indian people though effort has been made to include the respondents who are diverse in terms of age, education and other confounding variables.

\section{CONCLUSION}

The findings of this study highlight the importance of creating effective strategies for improving the awareness and education regarding fertility. This study also emphasizes the need for conducting further research in this area over a wider population so that effective educative programs can be planned.

Funding: No funding sources Conflict of interest: None declared

Ethical approval: Not required

\section{REFERENCES}

1. World Health Organization. WHO/MCH/91.9. Geneva: World Health Organization; Infertility: A
Tabulation of Available Data on Prevalence of Primary and Secondary Infertility; 1991.

2. Infecundity, infertility, and childlessness in developing countries. DHS Comparative Reports No 9. Calverton, Maryland, USA: ORC Macro and the World Health Organization; World Health Organization; 2004.

3. Unisa S. Childlessness in Andhra Pradesh, India: Treatment-seeking and consequences. Reprod Health Matters. 1999;7:54-64.

4. World Health Organization. Report of the Meeting on the Prevention of Infertility at the Primary Health Care Level. 1984, WHO, Geneva, Google Scholar WHO/MCH/84.4; 1983:12-6.

5. IIPS M, Macro OR. National Family Health Survey (NFHS-3), 2005-2006. Mumbai: IIPS. 2007.

6. Bunting L, Tsibulsky I, Boivin J. Fertility knowledge and beliefs about fertility treatment: findings from the international fertility decision-making study. Hum Reprod. 2013;28:385-97.

7. Animasahun VJ, Tijani AM, Amoran OE Contraception and Infertility among Couples in Sagamu Local Government Area, South-West, Nigeria Internat J Scientif Study. 2013;1(3):39-45.

8. Lisbet S. Lundsberg, Lubna Pal, Aileen M. Gariepy. Knowledge, attitudes, and practices regarding conception and fertility: a population-based survey among reproductive-age United States women mar 2014:101(3):767-74.

9. Dattijo L, Andreadis N, Aminu B. Knowledge of Infertility Among Infertile Women in Bauchi, Northern Nigeria.international J Women's Health and Reproduct Sci. 2016;4(3):103-9.

Cite this article as: Nayak UA, Ramakrishnan KG, Venkateswar KN, Vijayshree M. Dissecting the rural Indian women's knowledge, attitude and practice about infertility. Int J Reprod Contracept Obstet Gynecol 2017;6:3311-3. 